\title{
Habitable Zonen
}

\section{Erhard Taverna}

Dr. med., Mitglied der Redaktion

Frühmorgens leuchten Berghänge auf, es riecht nach frisch gemähtem Gras, Schwalben sammeln sich zu Schwärmen. Nachts rückt der Orion näher, und heller schimmert das Band der Milchstrasse.

Nach Hubble und Kepler soll demnächst das JamesWebb-Weltraumteleskop die Erde umkreisen. Die Atmosphäre von Exoplaneten lässt sich im Infrarotbereich besonders gut untersuchen. Sauerstoff und Methan sind die Indikatoren für Leben auf Gesteinsplaneten, die um die Mehrzahl der roten Zwergsonnen kreisen. Wo es Wasser gibt, könnte es erdähnlich zugehen. Die Astrophysik ist eine faszinierende Wissenschaft, weil sie äusserste Präzision mit kühnsten Spekulationen zusammendenkt. Eine Dokumentation des TV-Senders ARTE zeigt, wie führende Forscher sich eine unbemannte Erkundung zu einem fiktiven Exoplaneten MINERVA vorstellen. Im Jahre 2157 soll ein unbemanntes Raumschiff gleichen Namens einen fünfzigjährigen Flug beginnen. Ein Mehrgenerationenwerk, vergleichbar dem Bau der Kathedralen.

Eine habitable Zone bedeutet, dass Abstand zur Sonne, Umlaufbahn, Eigenrotation, Planetenachse und vieles Weitere günstige Voraussetzungen für die Entwicklung organischen Lebens bieten. Je erdähnlicher, desto habitabler. «Willst du immer weiter schweifen? Sieh, das Gute liegt so nah. Lerne nur das Glück ergreifen", möchte man mit Goethe sagen. Wozu Lichtjahre ent-

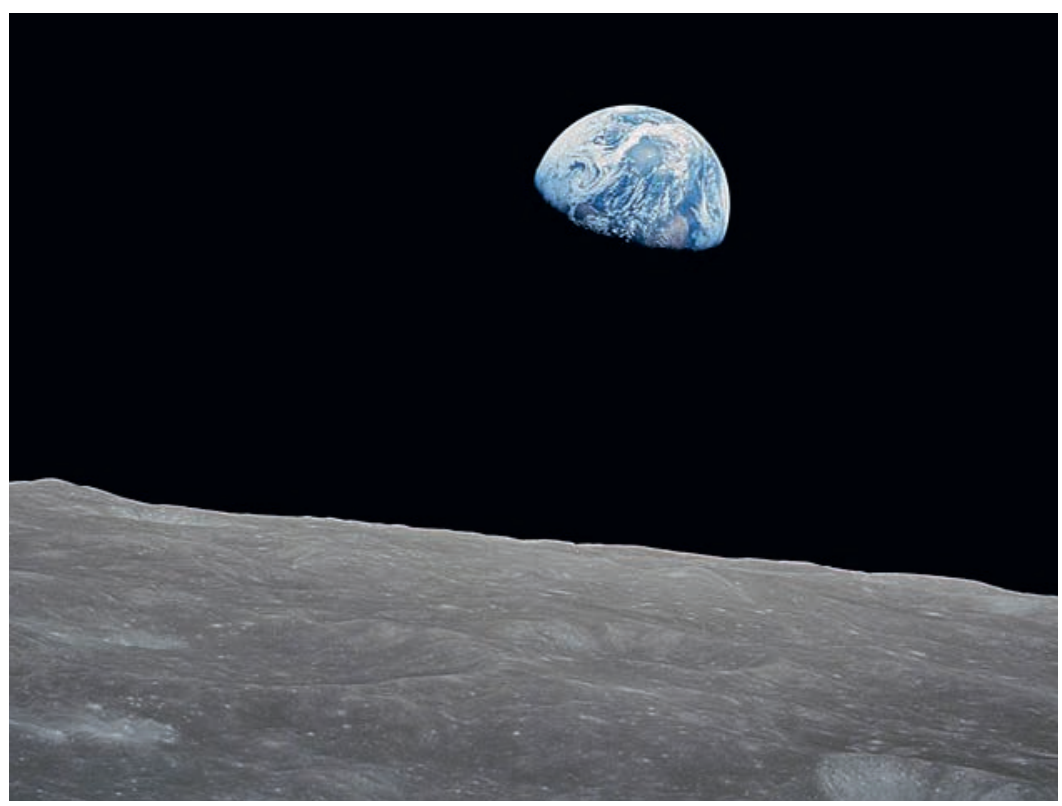

«Earthrise»: Erdaufgang über dem Mondhorizont, aufgenommen 1968 (Bild: NASA). fernt das Unerreichbare suchen? Wer sein eigenes Haus nicht in Ordnung hält, bringt keine Expeditionen zustande. Die Klimadebatte ist in vollem Gange, sie beeinflusst Wahlen, aber kaum noch unser destruktives Verhalten. Der Homo sapiens lebt mental im Holozän. Ein Jäger und Sammler, ein atomar hochgezüchteter Raubaffe. Zuerst kommen die anstehenden Hausaufgaben, dann vielleicht der Mond oder der Mars. Sonst kommt vielleicht gar nichts mehr.

Die Experten diskutieren über Plasma- und Fusionsantriebe, über Helium 3, das auf dem Mond zu gewinnen wäre. Das Riesending muss, wie die jetzige Weltraumstation im All zusammengebaut, eine 20 Tonnen schwere Landefähre transportieren. Wie Discovery auf dem Mars wird diese die unbekannte Oberfläche erkunden und die Resultate zur Erde signalisieren. Das Unterfangen ist so anspruchsvoll, dass nur die Zusammenarbeit grosser Nationen das Vorhaben ermöglichen würde. Mit anderen Worten: Es muss auf dieser Welt Frieden herrschen, die enormen Rüstungsausgaben werden in die Raumfahrt kanalisiert, die Menschen müssen ihre Bedürfnisse und die Ressourcen in ein Gleichgewicht bringen. Das klingt alles sehr utopisch und dürfte auch in 100 Jahren kaum verwirklicht sein. Andererseits läuft uns die Zeit davon. Minerva, ein schöner Traum. Die technischen Entwicklungen müssten noch lange weiterlaufen, mit unabsehbaren Folgen für uns Bewohner der habitablen Zone. Denn die Vorfahren von Lascaux sind uns näher als die Maschinenmenschen der übernächsten Generationen. Was sich durch alle Eiszeiten bewährte, ist nicht für den Weltraum geschaffen. Wir aber schreiten fort vom Biotop zum Technotop. Die geologische Tiefenzeit bekommt eine Fortsetzung namens Anthropozän. Der umstrittene Begriff suggeriert eine übermenschliche Langlebigkeit und Fortdauer der menschlichen Spezies, die ihre Evolution selbst in die Hand nimmt. Sollte das Phantasieprodukt Minerva Fahrt aufnehmen, werden wir uns in unseren Nachfahren nicht mehr erkennen. Jahrzehnte dauernde Reisen zu zweiten und dritten Erden, ein synthetisches Leben, halb Mensch, halb Roboter, gesteuert durch künstliche Intelligenzen. Eine befriedete Erde mag es vielleicht geben. In einer habitablen Zone, mit geklonten Schwalben unter gläsernen Kuppeln und Düften aus der Dose. 